\title{
Pain intensity and mental health quality of life in veterans with mental illnesses: the intermediary role of physical health and the ability to participate in activities
}

\author{
Emre Umucu ${ }^{1}\left(10\right.$ - Antonio Reyes ${ }^{2} \cdot$ Paul Carrola $^{3} \cdot$ Thenral Mangadu $^{4} \cdot$ Beatrice Lee $^{1} \cdot$ Jessica M. Brooks ${ }^{5}$. \\ Karen L. Fortuna ${ }^{6} \cdot$ Diana Villegas $^{1} \cdot$ Chung-Yi Chiu $^{7}$. Carolina Valencia ${ }^{1}$
}

Accepted: 12 September 2020 / Published online: 24 September 2020

C) Springer Nature Switzerland AG 2020

\begin{abstract}
Purpose The purpose of this study was to examine the intermediary role of physical health quality of life and ability to participate social roles and activities in the relationship between pain intensity and mental health quality of life in veterans with mental illnesses.

Methods This is a cross-sectional correlational design study. Our participants are 156 veterans with self-reported mental illness $\left(M_{\text {age }}=37.85 ; \mathrm{SD}_{\text {age }}=10.74\right)$. Descriptive, correlation, and mediation analyses were conducted for the current study. Results Pain intensity was negatively correlated with physical health QOL, ability to participate in social roles and activities, and mental health QOL. Physical health QOL and ability to participate in social roles and activities were positively associated with mental health QOL, respectively. Physical health QOL was positively correlated with a ability to participate in social roles and activities. Study results indicate that the effect of pain intensity on mental health QOL can be explained by physical health QOL and ability to participate.

Conclusions Specific recommendations for practitioners include implementing treatment goals that simultaneously focus on physical health and ability to participate in social roles and activities for clients who present with both physical pain and low mental health QOL.
\end{abstract}

Keywords Quality of life $\cdot$ Veterans $\cdot$ Mental illness $\cdot$ Participation $\cdot$ Pain

Emre Umucu

eumucu@utep.edu

1 Department of Rehabilitation Sciences, The University of Texas at El Paso, 500 W University Ave, El Paso, TX 79968, USA

2 Division of Special Education and Counseling, CA State University - Los Angeles, Los Angeles, CA, USA

3 Department of Educational Psychology and Special Services, The University of Texas at El Paso, El Paso, TX, USA

4 Department of Public Health Sciences, The University of Texas at El Paso, El Paso, TX, USA

5 Department of Psychiatry, School of Medicine and Public Health, University of Wisconsin - Madison, Madison, WI, USA

6 The Geisel School of Medicine at Dartmouth, Dartmouth College, Concord, NH, USA

7 Department of Kinesiology and Community Health, University of Illinois Urbana Champaign, Champaign, IL, USA
Due to the intense experiences associated with deployment and combat, Veterans are at high risk of developing a mental illness [1]. More than 1.7 million Veterans received treatment in a Department of Veterans Affairs (VA) mental health specialty program in fiscal year 2018 [2], and this number may not fully reflect the problem of mental illness among Veterans given that many do not seek treatment through the VA [1]. Mental illness is associated with poorer mental health quality of life, which is comprised of a combination of the perception of mental health and functional effects of mental illness [3]. Mental health quality of life provides a useful understanding of the burden of mental illness because it appreciates that the impact of mental illness may be variable among individuals. Additional research is needed to better understand predictors of mental health quality of life and well-being for Veterans with a mental illness [4, 5].

Veterans are also at high risk of developing chronic pain due to the extraordinary physical stress associated with military service [6]. Studies indicate that $66 \%$ of veterans 
report experiencing pain with $9 \%$ reporting severe pain [7]. Over $50 \%$ of Veterans who receive care at the VA are diagnosed with musculoskeletal pain [8] and a survey of Veterans found a high prevalence of headaches (54\%), joint pain (45\%), back pain, (44\%), muscle pain (33\%), and abdominal pain $(23 \%)$ [9]. Researchers argue that addressing and treating pain, including addressing opioid use disorder (OUD) risk, is an increasingly important challenge for the VA due to the aging population and growth in number of Veterans with chronic pain related to recent military service [10]. Prior studies also indicate that veterans with chronic pain and comorbid psychiatric disorders are more likely to receive opioids than pain patients without comorbid psychopathology, these diagnoses are also associated with prescription of high opioid doses [11].

For Veterans who experience pain, the effects can extend to every aspect of their life. Pain can interfere with participation in daily activities and is associated with higher levels of emotional distress [12]. Thus, it is not surprising that pain and mental illnesses are commonly comorbid for Veterans [13]. Research suggests that pain is strongly associated with symptoms of anxiety, depressive disorders, suicidal ideation, and PTSD [13-15]. Poundja et al. [16] found that both pain severity and pain interference are negatively correlated with mental health quality of life in Canadian veterans suffering from traumatic stress. Boakye et al. [17] examined healthrelated quality of life in veterans with spinal cord injury (SCI) and found that a visual analog pain score was the most important predictor of worsened mental health quality of life scores. Likewise, Kazis et al. [18] reported that chronic low back pain is negatively associated with mental health quality of life in patients served by the VA. These studies and others highlight the importance of better understanding the underlying mechanisms by which pain intensity impacts mental health quality of life for Veterans.

Mental health quality of life and pain are also associated with physical health quality of life (i.e., ratings of physical health and the ability to carry out physical activities) and participation in social roles and activities. The ability to participate in social roles and activities improves mental health while decreasing mental health symptoms [19]. Social participation is also strongly associated with social support, which has long been known to play an important role in protecting against negative effects of stress and mental illness, see e.g., [20]. Research suggests that physical health quality of life is associated with greater ability to participate in social activities, and consequentially enhancing social connectedness and its health benefits. For example, longitudinal data from the Veterans Health Study, Ren et al. [21] shows that physical health is associated with a person's ability to participate and maintain social relationships and stronger social support.
Additionally, Rippentrop et al. [22] found that physical health quality of life is positively related to mental health quality of life for individuals with chronic pain. Similarly, in a study of Vietnam veterans, Schnurr et al. [23] found that reported physical health quality of life is related to PTSD symptom severity. General population studies also indicate that greater pain intensity is associated with greater interference with social participation and physical and recreational activities [24-26]. In a study of veterans, Naylor et al. [15] found a positive correlation between pain intensity and functional factors including physical disability and social support. Overall, research supports that pain, physical health quality of life, and the ability to participate in social functions are all related and contribute to mental health quality of life. Likely, the relationship between pain intensity and mental health quality of life is influenced by physical health quality of life and participation in social roles and activities.

Although existing studies have examined the relationship between pain, social relationships, and physical and mental health quality of life for Veterans, none have systematically examined these factors together to better understand their impact on mental health quality of life. Therefore, the purpose of this study was to examine the intermediary role of physical health quality of life and ability to participate in social roles and activities in the relationship between pain intensity and mental health quality of life in veterans with mental illnesses. We hypothesized that (a) increased pain intensity is associated with reduced physical and mental health quality of life, (b) decreased physical health quality of life is associated with lower levels of the ability to participate social roles and activities, and (c) reduced ability to participate social roles and activities negatively affect mental health quality of life in veterans with mental illnesses. Health care systems could use this valuable information to potentially improve value of services for Veterans with mental illnesses by addressing modifiable risk factors such as physical health QOL and ability to participate through treatment.

\section{Methods}

\section{Design and procedure}

This cross-sectional study was reviewed and approved as an exempt study by the Institutional Review Board by the University of Texas at El Paso. We collected data from Amazon's MTurk, a crowdsourcing tool enabling MTurk Workers to access and complete Human Intelligence Tasks (HITs). MTurk has been considered as a valid, diverse, reliable, and cost-effective large data collection tool [27, 28]. Based on MTurk options, we restricted participants to be residents in 
the United States who have military experience. We shared a Qualtrics survey link with participants. All participants read an online consent form and agreed to be participant in this study. All participants received $\$ 4.00$ upon completing the online survey.

\section{Measures}

\section{Pain intensity}

Pain intensity was assessed using the PROMIS ${ }^{\circledR}$ Numeric Rating Scale v.1.0-Pain Intensity 1a [29-31]. It is a oneitem measure that asks respondents to rate their pain on average, ranging from 0 (no pain) to 10 (worst imaginable pain) over the past 7 days. Higher scores indicate higher levels of pain intensity.

\section{Physical health quality of life}

Physical health QOL was assessed using the PROMIS ${ }^{\circledR}$ Scale v1.2-Global Health Physical 2a [32]. It is a 2-item measure that asks respondents to rate their physical health (ranging from 1 [poor] to 5 [excellent]) and their ability to carry out daily physical activities (ranging from 1 [not at all] to 5 [completely]). Higher scores indicate higher physical health QOL. Total raw scores were converted into $T$ scores. The Cronbach's alpha coefficient for the PROMIS global physical health in the present study was computed to be 0.52 .

\section{Ability to participate in social roles and activities}

Ability to participate was assessed using the PROMIS ${ }^{\circledR}$ Item Bank v2.0-Ability to Participate in Social Roles and Activities-Short Form 4a [33]. It is a 4-item measure that asks respondents to rate their perceptions on their ability to perform their social functions, ranging from 1 (always) to 5 (never). Higher scores indicate higher levels of ability to participate. Total raw scores were converted into $T$ scores. The Cronbach's alpha coefficient for the PROMIS ability to participate in social roles and activities in the present study was computed to be 0.90 .

\section{Mental health QOL}

Mental health QOL was assessed using the PROMIS ${ }^{\circledR}$ Scale v1.2-Global Health Mental 2a [32]. It is a 2-item measure that asks respondents to rate their mental health and satisfaction with social connections, ranging from 1 (poor) to 5 (excellent). Higher scores indicate higher mental health QOL. Total raw scores were converted into $T$ scores. The Cronbach's alpha coefficient for the PROMIS global mental health in the present study was computed to be 0.77 .

\section{Data analysis}

All analyses were performed using the Statistical Package for the Social Sciences (SPSS; version 25). Descriptive statistics were computed to provide information about the demographic characteristics and for the independent variable, mediators, and dependent variable. Correlation analysis was conducted to examine relationships among variables. Finally, a serial mediation analysis was conducted to examine physical health QOL and ability to participate as mediators between pain intensity and mental health QOL. The SPSS PROCESS 3.4.1 [34] was used to conduct mediation analysis. A bootstrapping approach was also used to test the significance of indirect effects of pain intensity on mental health QOL with 5000 bootstrap samples through (a) physical health QOL, (b) ability to participate in social roles and activities, and (c) both physical health QOL and ability to participate. Although there is not a consensus how many bootstrap samples should be generated, researchers recommended at least 5000 resamples for final reporting [35].

\section{Results}

\section{Participants}

The total number of participants were 156 veterans with selfreported mental illnesses. Participants ranged in age from 23 to 72 , with an average of 37.85 years old $(S D=10.74)$. Most participants were males $(66.7 \%)$. The majority of participants identified as Caucasians (69.9\%) and married (52.6\%). Regarding educational level, 39\% obtained a bachelor's degree, followed by some college credit without a degree (23.1\%), an associate's degree (13.5\%), a graduate degree (12.2\%), a trade/technical/vocational training (7.1\%), and a high school degree (5.8\%). Many participants served in the Army (55.8\%), followed by Air Force (17.9\%), Navy (12.2\%), Marine Corps (10.3\%), and Coast Guard (3.8\%). In terms of mental illnesses, participants reported at least one type of mental illnesses, including $64.7 \%$ reported depression, $57.1 \%$ reported anxiety, $35.3 \%$ reported PTSD, $10.3 \%$ reported substance use disorder, $4.5 \%$ reported bipolar disorder, $4.5 \%$ reported personality disorder, and $3.9 \%$ reported others.

\section{Descriptive statistics}

Participants' pain intensity scores ranged from 0 to 10 with an average of $3.44(S D=2.41)$. Physical health QOL $T$ scores ranged from 23.40 to 63.30 with an average of 45.10 $(S D=8.03)$. Ability to participate in social roles and activities $T$ scores ranged from 31.80 to 64.20 with an average of $47.78(S D=8.40)$. Mental health QOL $T$ scores ranged from 
25.80 to 64.60 with an average of $40.83(S D=8.40)$. After examining $T$ scores, we found that $14.7 \%$ and $60.3 \%$ of the participants had physical health quality of life $T$ scores of above and below the mean, respectively; $11.5 \%$ and $88.5 \%$ of the participants had mental health quality of life $T$ scores of above and below the mean, respectively; and $30.8 \%$ and $60.3 \%$ of the participants had ability to participate in social roles and activities $T$ scores of above and below the mean, respectively.

\section{Correlation analysis}

Pain intensity was negatively correlated with physical health QOL $(r=-0.56, p<0.001)$, ability to participate in social roles and activities $(r=-0.54, p<0.001)$, and mental health QOL $(r=-0.33, p<0.001)$. Physical health QOL $(r=0.44, p<0.001)$ and ability to participate in social roles and activities $(r=0.55, p<0.001)$ were positively associated with mental health QOL, respectively. Physical health QOL was positively correlated with an ability to participate in social roles and activities $(r=0.55, p<0.001)$.

\section{Mediation analysis}

The serial mediation model is presented in Fig. 1. Pain intensity was significantly associated with mental health QOL $(c=-0.33, p<0.001)$. Pain intensity was significantly associated with physical health QOL $\left(a_{1}=-0.56\right.$, $p<0.001)$ and was significantly associated with ability to participate in social roles and activities after controlling for physical health QOL $\left(a_{2}=-0.34, p<0.001\right)$. Physical health QOL was significantly associated with ability to participate in social roles and activities after controlling for pain intensity $\left(d_{21}=0.35, p<0.001\right)$. Additionally, physical health QOL was significantly associated with mental health
QOL after controlling for pain intensity and ability to participate in social roles and activities $\left(b_{1}=0.22, p<0.05\right)$. Ability to participate in social roles and activities was significantly associated with mental health QOL after controlling for pain intensity and physical health QOL $\left(b_{2}=0.45\right.$, $p<0.001$ ).

Importantly, pain intensity was no longer significantly associated with mental health QOL after controlling for physical health QOL and ability to participate in social roles and activities $\left(c^{\prime}=0.04, p=0.65\right)$. This suggests that physical health QOL and the ability to participate in social roles and activities mediated the relationship between pain intensity and mental health QOL. In addition, results using the PROCESS with 5000 bootstrap samples, demonstrated that the indirect paths were significant because the $95 \%$ confidence intervals did not contain zero, suggesting that the indirect effects were different from zero. The indirect effect of pain intensity through physical health QOL on mental QOL was significant $\left(a_{1} b_{1}=-0.12 ; 95 \% \mathrm{CI}[-0.23,-0.02]\right.$. The indirect effect of pain intensity through ability to participate on mental health QOL was significant $\left(a_{2} b_{2}=-0.15 ; 95 \%\right.$ CI $[-0.25,-0.07]$. The indirect effect of pain intensity through physical health QOL and ability to participate in social roles and activities on mental health QOL was significant $\left(a_{1} d_{21} b_{2}=-0.09 ; 95 \%\right.$ CI $[-0.16,-0.04]$. Overall, the mediation analysis indicated that the effect of pain intensity on mental health QOL can be explained by physical health QOL and ability to participate in social roles and activities.

\section{Discussion}

Our analyses provide novel insights by clarifying the intermediary role of physical health quality of life and ability to participate in social roles and activities in the relationship between pain intensity and mental health quality of life in veterans with mental illnesses. Similar associations were

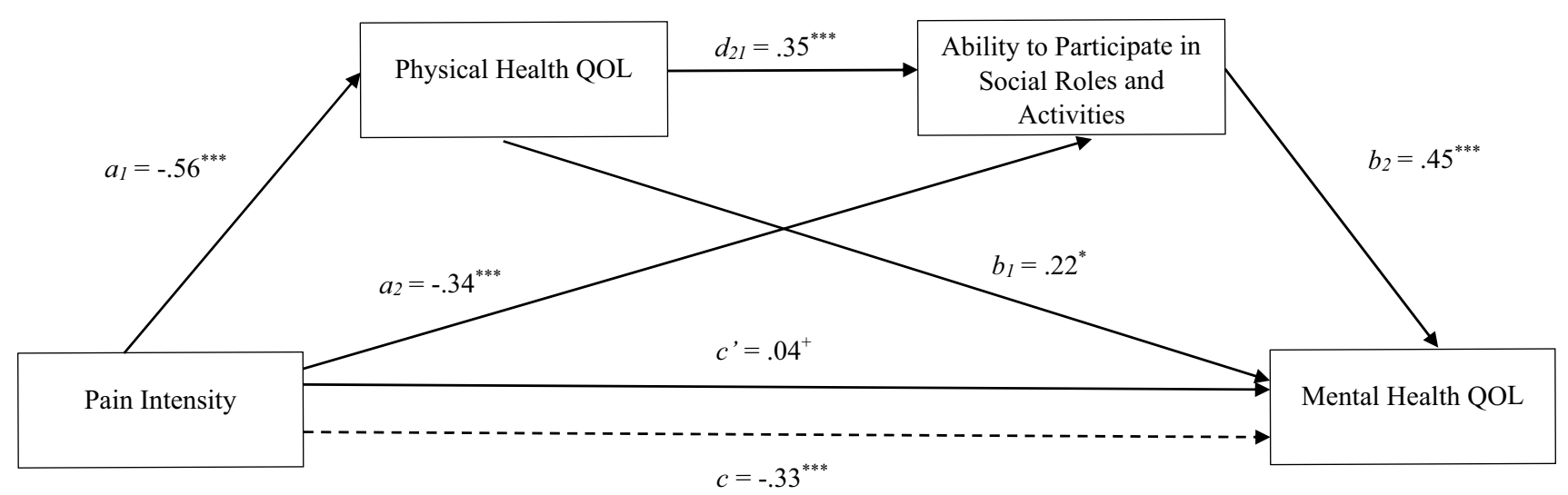

Fig. 1 Standardized path coefficients for serial mediation analysis on the relationship between pain intensity and mental health QOL. Note: Dotted line denotes the total effect of pain intensity on mental health QOL when mediators are not included. $* * * p<0.001 ; *^{*} p<0.05 ;{ }^{+} p=.65$ 
found between pain intensity and physical health QOL, ability to participate in social roles and activities, and mental health QOL, respectively. However, one key finding is that the initial association between pain intensity and mental health QOL was mediated by physical QOL and ability to participate in social roles and activities. This is valuable information because the negative effect of pain on mental health QOL could be mitigated by increasing physical health QOL and ability to participate in social roles and activities and potentially improve value of services for veterans with mental illnesses by addressing these modifiable risk factors through treatment.

Physical health QOL and ability to participate in social roles and activities directly contribute to veterans' level of pain and mental health independently. As such, reduced mental health symptoms in veterans who also have identified pain symptoms can be achieved through improving physical health and ability to participate in social roles and activities in veterans with mental illnesses. Strategies to improve physical health and ability to participate in social roles and activities are effective treatment supplements for rehabilitation and mental health professionals to integrate into their psychotherapeutic or psychoeducational interventions for veterans with mental illnesses who have low mental health QOL due to pain intensity. In addition, increasing evidence is accumulating for the effectiveness of multidisciplinary pain management strategies [36-40], including the VA's own stepped care pain management approach, to manage severe chronic pain [41]. Supplementing traditional psychotherapeutic or psychoeducational pain management interventions with self-directed client activities constitutes an empirically supported approach to treatment. This approach is supported by recent research that has highlighted the importance of self-managed (i.e., initiated and managed by the client) interventions [42]. In their study, Harding et al. [42] found that while veterans with chronic pain psychological comorbidities were more likely to seek provider managed interventions, they were more likely to use self-managed interventions overall. This suggests that veterans are more willing to initiate self-managed interventions for chronic pain in general. Self-managed interventions can also be implemented through more direct ways through integrated primary and behavioral health care, see e.g., [43].

The specific relationships between pain intensity, mental health, physical health, and ability to participate in social roles and activities are central data that inform integrated treatment practices. This study provides important evidence that supports the argument for both multidisciplinary assessment and treatment. While multidisciplinary and holistic models of treatment have long been advocated in the mental health profession [44], the direct relationship between physical health and ability to participate in social roles and activities with patient's experienced pain provided by this study supports the benefit of physical health and ability to participate in social roles and activities as our study provides the promising approach to complement the existing services. These factors could also be used to better guide future studies and clinical trials from the newly developed Pain Management Collaboratory [45], which has the main goal of developing the capacity to implement cost-effective large-scale pragmatic clinical research in military and veteran health care delivery organizations focusing on nonpharmacological approaches to pain management and other comorbid conditions.

The value of this study is highlighted by the overall lack of research directly exploring the relationships between pain intensity, mental health, physical health, and social engagement. Historically, medical and mental health treatment have been viewed by health care and policy makers as separate [46], which has created barriers for overall treatment and negatively impacts help seeking behaviors for persons with both medical and mental health concerns. This is specifically relevant for veteran populations who have experienced increased rates of mental health disorders [47] and high rates of comorbidity between pain and mental health diagnoses $[13,48]$. The results of the current study not only support the importance of mental health professionals using holistic interventions but also supports previous research that cites the benefit of integrated behavioral and primary healthcare, see e.g., $[49,50]$.

Although there is a lack of research examining the intermediary role of physical health QOL and ability to participate in social roles and activities for the relationship between pain intensity and mental health QOL among veterans, it is also important to report that our findings are partially consistent with some studies with different populations. For example, participation restriction was found to be a mediator between pain intensity and depression symptoms and QOL in individuals with spinal cord injury, respectively [51]. Nguyen et al. [52] examined whether changes in mental health was associated with improvements in pain and function scores 1 year after total hip arthroplasty. Their findings revealed that greater improvements in pain and function were related to greater improvements in mental health. In a sample with chronic low back pain, authors [53] reported that higher somatic symptoms were related to lower healthrelated QOL independent of depression and other comorbid disorders [52]. Interestingly, in a sample with chronic pain, authors [54] found that pain intensity and duration were found to have a minor role for QOL and disability although psychological variables (e.g., depression) were found to have a strong association with QOL and disability. Overall, these findings revealed that pain-related, psychological, and social factors are important for QOL although the magnitude of impacts of these variables on QOL may change based on the population. As indicated above, it is important to have 
holistic and multidisciplinary treatment options to achieve optimal rehabilitation and health outcomes, which could eventually improve QOL.

Additionally, as this manuscript is being written, the U.S. is facing a global pandemic from the COVID-19 virus. The physical and social restrictions brought on by this pandemic limit social participation and is negatively impacting the mental health quality of life for all persons and may have elevated effects for groups that are already experiencing physical and mental health issues. Besides, the current COVID-19 pandemic has led to changes in mental health care (e.g., transition to telehealth service delivery), disruptions in daily life, and greater psychological distress that are unique to veterans $[55,56]$. Since many veterans may already experience social isolation and activity restrictions, it is especially important to facilitate discussions around maintaining and improving positive social connections while following social distance measures, encourage the use of adaptive coping strategies to manage difficulties, and provide psychoeducation on how the COVID-19 pandemic might trigger trauma-related memories [57]. Our study provides further implications for clinicians to consider when working with Veterans with mental illnesses in the COVID-19 crisis. For instance, clinicians may take Veterans with mental illnesses' physical health QOL and ability to participate into consideration as the pandemic may have led to dramatic shifts in Veteran's daily life, which can further influence their mental health quality of life. During a public health crisis as such, Veterans with mental illnesses may benefit from individualized treatment plans that are tailored to their personal and contextual factors.

Some limitations of this study will need to be addressed by future research. First, our design is incapable of evaluating the causal mechanisms that underlie the explored relationships. Future studies should utilize longitudinal designs to explore the temporal associations of these variables. Nevertheless, these findings provide important information that could ultimately improve the value of clinical services already available for Veterans with mental illnesses. Second, data for this study come primarily from veterans with heterogeneity of self-reported mental illness. Therefore, since different mental illnesses have different underlying pathophysiological mechanisms, associations could change by exploring mental illnesses separately. Third, in addition to pain intensity, future studies should explore pain interference, which is defined as the extent that pain negatively impacts engagement in social, cognitive, emotional, physical, and recreational activities. Fourth, female veterans seem to be slightly over-represented in our sample and the percentage of subjects with a bachelor's degree seems to be higher than the average in veterans (15.7-20.1\%) [58]. Fifth, we measured pain intensity with a single item. Given the complexity of pain and its impact on QOL (e.g., pain and mental health and physical health relationships), future studies may consider measuring pain intensity with a scale that has a strong evidence of discriminant validity. Finally, it is important to take into consideration that there may be some conceptual overlap between the concepts examined in our study, which we suggest that future research should use more robust means of measurements.

In summary, these findings support continued efforts to provide multidisciplinary, holistic and integrated health care for the management of pain conditions for veterans with mental illnesses. Specific recommendations for practitioners include implementing treatment goals that simultaneously focus on physical health and ability to participate in social roles and activities for clients who present with both physical pain and low mental health QOL. While many practitioners may use patients' levels of physical health and social engagement as a measure to predict pain and mental health symptom reduction, identifying these two factors (physical health QOL and social activity) more directly in conceptualizing client's mental health symptoms with identified pain symptoms may help developing more targeted intervention, especially for veterans with mental illness.

Acknowledgements We would like to thank Renee Viramontes and Cherylanne Hunter for their support in our lab, the Veteran VVellBeing $\mathrm{Lab}\left(\mathrm{V}^{3}\right)$.

Funding This study is funded by the College of Health Sciences of the UT-El Paso (PI: Dr. Emre Umucu).

\section{Compliance with ethical standards}

Conflict of interest The authors declare that they have no conflict of interest.

Ethical approval This study was reviewed and approved as exempt study by the Institutional Review Board by the University of Texas at El Paso (IRB ID: 1153068-2).

Informed consent Informed consent was obtained from all participants in this study.

\section{References}

1. Vogt, D., Fox, A. B., \& Di Leone, B. A. L. (2014). Mental health beliefs and their relationship with treatment seeking among U.S. OEF/OIF Veterans. Journal of Traumatic Stress, 27(3), 307-313. https://doi.org/10.1002/jts.21919.

2. U.S. Department of Veterans Affairs. (2020). VA mental health services. Retrieved August 8, 2020, from https://www.va.gov/ health-care/health-needs-conditions/mental-health/.

3. Riley, W. T., Rothrock, N., Bruce, B., Christodolou, C., Cook, K., Hahn, E. A., et al. (2010). Patient-reported outcomes measurement information system (PROMIS) domain names and definitions revisions: further evaluation of content validity in IRT-derived item 
banks. Quality of Life Research, 19(9), 1311-1321. https://doi. org/10.1007/s11136-010-9694-5.

4. Umucu, E., Villegas, D., Viramontes, R., Jung, H., \& Lee, B. (2020). Measuring grit in veterans with mental illnesses: Examining the model structure of grit. Psychiatric Rehabilitation Journal. https://doi.org/10.1037/prj0000420.

5. Umucu, E. (2020). Examining the structure of the PERMA theory of well-being in veterans with mental illnesses. Rehabilitation Counseling Bulletin. https://doi.org/10.1177/0034355220957093.

6. Higgins, D. M., Kerns, R. D., Brandt, C. A., Haskell, S. G., Bathulapalli, H., Gilliam, W., et al. (2014). Persistent pain and comorbidity among operation enduring freedom/operation Iraqi Freedom/Operation New Dawn Veterans. Pain Medicine, 15(5), 782-790. https://doi.org/10.1111/pme.12388.

7. Nahin, R. L. (2017). Severe pain in veterans: The effect of age and sex, and comparisons with the general population. The Journal of Pain, 18(3), 247-254. https://doi.org/10.1016/j.jpain.2016.10.021.

8. Goulet, J. L., Kerns, R. D., Bair, M., Becker, W. C., Brennan, P., Burgess, D. J., et al. (2016). The musculoskeletal diagnosis cohort: Examining pain and pain care among veterans. Pain, 157(8), 1696-1703. https://doi.org/10.1097/j.pain.0000000000 000567.

9. Kang, H. K., Mahan, C. M., Lee, K. Y., Magee, C. A., \& Murphy, F. M. (2000). Illnesses among united states veterans of the gulf war: A population-based survey of 30,000 veterans. Journal of Occupational and Environmental Medicine, 42(5), 491-501.

10. Frank, J. W., Carey, E., Nolan, C., Kerns, R. D., Sandbrink, F., Gallagher, R., et al. (2018). Increased nonopioid chronic pain treatment in the Veterans Health Administration, 2010-2016. Pain Medicine, 20(5), 869-877. https://doi.org/10.1093/pm/pny149.

11. Morasco, B. J., Duckart, J. P., Carr, T. P., Deyo, R. A., \& Dobscha, S. K. (2010). Clinical characteristics of veterans prescribed high doses of opioid medications for chronic non-cancer pain. Pain, 151(3), 625-632. https://doi.org/10.1016/j.pain.2010.08.002.

12. Matthias, M. S., Kukla, M., McGuire, A. B., \& Bair, M. J. (2016). How do patients with chronic pain benefit from a peer-supported pain self-management intervention? A qualitative investigation. Pain Medicine, 17(12), 2247-2255. https://doi.org/10.1093/pm/ pnw138.

13. Plagge, J. M., Lu, M. W., Lovejoy, T. I., Karl, A. I., \& Dobscha, S. K. (2013). Treatment of comorbid pain and PTSD in returning Veterans: A collaborative approach utilizing behavioral activation. Pain Medicine, 14(8), 1164-1172. https://doi.org/10.1111/ pme.12155.

14. Von Korff, M., \& Simon, G. (1996). The Relationship Between Pain and Depression. British Journal of Psychiatry, 168(S30), 101-108. https://doi.org/10.1192/S0007125000298474.

15. Naylor, J. C., Wagner, H. R., Johnston, C., Elbogen, E. E., Brancu, M., Marx, C. E., et al. (2019). Pain intensity and pain interference in male and female Iraq/Afghanistan-era Veterans. Women's Health Issues, 29, S24-S31. https://doi.org/10.1016/j. whi.2019.04.015.

16. Poundja, J., Fikretoglu, D., Guay, S., \& Brunet, A. (2007). Validation of the French version of the brief pain inventory in Canadian veterans suffering from traumatic stress. Journal of Pain and Symptom Management, 33(6), 720-726. https://doi.org/10.1016/j. jpainsymman.2006.09.031.

17. Boakye, M., Moore, R., Kong, M., Skirboll, S. L., \& Arrigo, R. T. (2013). Health-related quality-of-life status in Veterans with spinal disorders. Quality of Life Research, 22(1), 45-52. https:// doi.org/10.1007/s11136-012-0121-y.

18. Kazis, L. E., Miller, D. R., Clark, J., Skinner, K., Lee, A., Rogers, W., et al. (1998). Health-Related quality of life in patients served by the Department of Veterans Affairs: Results from the Veterans Health Study. Archives of Internal Medicine, 158(6), 626-632. https://doi.org/10.1001/archinte.158.6.626.
19. Cohen, S. (2004). Social relationships and health. American Psychologist, 59(8), 676-684. https://doi. org/10.1037/0003-066X.59.8.676.

20. Kessler, R. C., \& McLeod, J. D. (1985). Social support and mental health in community samples. In S. Cohen \& S. L. Syme (Eds.), Social support and health (pp. 219-240). San Diego, CA: Academic Press.

21. Ren, X. S., Skinner, K., Lee, A., \& Kazis, L. (1999). Social support, social selection and self-assessed health status: results from the veterans health study in the United States. Social Science \& Medicine, 48(12), 1721-1734. https://doi.org/10.1016/S0277 -9536(99)00069-6.

22. Elizabeth Rippentrop, A., Altmaier, E. M., Chen, J. J., Found, E. M., \& Keffala, V. J. (2005). The relationship between religion/spirituality and physical health, mental health, and pain in a chronic pain population. Pain, 116(3), 311-321. https://doi. org/10.1016/j.pain.2005.05.008.

23. Schnurr, P. P., Hayes, A. F., Lunney, C. A., McFall, M., \& Uddo, M. (2006). Longitudinal analysis of the relationship between symptoms and quality of life in veterans treated for posttraumatic stress disorder. Journal of Consulting and Clinical Psychology, 74(4), 707-713. https://doi.org/10.1037/0022-006X.74.4.707.

24. Avluk, O. C., Gurcay, E., Gurcay, A. G., Karaahmet, O. Z., Tamkan, U., \& Cakci, A. (2014). Effects of chronic pain on function, depression, and sleep among patients with traumatic spinal cord injury. Annals of Saudi Medicine, 34(3), 211-216. https://doi. org/10.5144/0256-4947.2014.211.

25. Cadogan, M. P., Edelen, M. O., Lorenz, K. A., Jones, M., Yosef, J., Hascall, T., et al. (2008). The relationship of reported pain severity to perceived effect on function of nursing home residents. The Journals of Gerontology: Series A, 63(9), 969-973. https:// doi.org/10.1093/gerona/63.9.969.

26. van Seventer, R., Serpell, M., Bach, F. W., Morlion, B., Zlateva, G., Bushmakin, A. G., et al. (2011). Relationships between changes in pain severity and other patient-reported outcomes: An analysis in patients with posttraumatic peripheral neuropathic pain. Health and Quality of Life Outcomes, 9, 17. https://doi. org/10.1186/1477-7525-9-17.

27. Goodman, J. K., Cryder, C. E., \& Cheema, A. (2013). Data collection in a flat world: The strengths and weaknesses of Mechanical Turk samples. Journal of Behavioral Decision Making, 26(3), 213-224. https://doi.org/10.1002/bdm.1753.

28. Rand, D. G. (2012). The promise of Mechanical Turk: How online labor markets can help theorists run behavioral experiments. Journal of Theoretical Biology, 299, 172-179. https://doi. org/10.1016/j.jtbi.2011.03.004.

29. Amtmann, D., Cook, K. F., Jensen, M. P., Chen, W.-H., Choi, S., Revicki, D., et al. (2010). Development of a PROMIS item bank to measure pain interference. Pain, 150(1), 173-182. https://doi. org/10.1016/j.pain.2010.04.025.

30. Cleeland, C. S., \& Ryan, K. M. (1994). Pain assessment: Global use of the Brief Pain Inventory. Annals, Academy of Medicine, Singapore, 23(2), 129-138.

31. Jensen, M. P. (2010). Measurement of pain. In S. M. Fishman, J. C. Ballantyne, \& J. P. Rathmell (Eds.), Bonica's management of pain (pp. 251-270). Philadelphia, PA: Williams \& Wilkins.

32. Hays, R. D., Schalet, B. D., Spritzer, K. L., \& Cella, D. (2017). Two-item PROMIS ${ }^{\circledR}$ global physical and mental health scales. Journal of Patient-Reported Outcomes, 1(1), 2. https://doi. org/10.1186/s41687-017-0003-8.

33. Hahn, E. A., DeWalt, D. A., Bode, R. K., Garcia, S. F., DeVellis, R. F., Correia, H., et al. (2014). New English and Spanish social health measures will facilitate evaluating health determinants. Health Psychology, 33(5), 490-499. https://doi.org/10.1037/hea00 00055. 
34. Hayes, A. F. (2017). Introduction to mediation, moderation, and conditional process analysis: A regression-based approach. New York: Guilford Press.

35. Preacher, K. J., \& Hayes, A. F. (2008). Asymptotic and resampling strategies for assessing and comparing indirect effects in multiple mediator models. Behavior Research Methods, 40(3), 879-891. https://doi.org/10.3758/BRM.40.3.879.

36. Flor, H., Fydrich, T., \& Turk, D. C. (1992). Efficacy of multidisciplinary pain treatment centers: A meta-analytic review. Pain, 49(2), 221-230. https://doi.org/10.1016/0304-3959(92)90145-2.

37. Gunreben-Stempfle, B., Grießinger, N., Lang, E., Muehlhans, B., Sittl, R., \& Ulrich, K. (2009). Effectiveness of an intensive multidisciplinary headache treatment program. Headache: The Journal of Head and Face Pain, 49(7), 990-1000. https://doi.org/10.111 1/j.1526-4610.2009.01448.x.

38. Håland Haldorsen, E. M., Grasdal, A. L., Skouen, J. S., Risa, A. E., Kronholm, K., \& Ursin, H. (2002). Is there a right treatment for a particular patient group? Comparison of ordinary treatment, light multidisciplinary treatment, and extensive multidisciplinary treatment for long-term sick-listed employees with musculoskeletal pain. Pain, 95(1), 49-63. https://doi.org/10.1016/S0304 -3959(01)00374-8.

39. Scascighini, L., Toma, V., Dober-Spielmann, S., \& Sprott, H. (2008). Multidisciplinary treatment for chronic pain: A systematic review of interventions and outcomes. Rheumatology, 47(5), 670-678. https://doi.org/10.1093/rheumatology/ken021.

40. Skouen, J. S., Grasdal, A. L., Haldorsen, E. M. H., \& Ursin, H. (2002). Relative cost-effectiveness of extensive and light multidisciplinary treatment programs versus treatment as usual for patients with chronic low back pain on long-term sick leave: Randomized controlled study. Spine, 27(9), 901-909.

41. Bair, M. J., Ang, D., Wu, J., Outcalt, S. D., Sargent, C., Kempf, C., et al. (2015). Evaluation of stepped care for chronic pain (ESCAPE) in veterans of the Iraq and Afghanistan conflicts: A randomized clinical trial. JAMA Internal Medicine, 175(5), 682689. https://doi.org/10.1001/jamainternmed.2015.97.

42. Harding, K., Day, M. A., Ehde, D. M., Wood, A. E., McCall, A., \& Williams, R. (2018). Mental and physical health correlates of pain treatment utilization among Veterans with chronic pain: A cross-sectional study. Military Medicine, 184(3-4), e127-e134. https://doi.org/10.1093/milmed/usy235.

43. Lenz, A. S., Dell'Aquila, J., \& Balkin, R. S. (2018). Effectiveness of integrated primary and behavioral healthcare. Journal of Mental Health Counseling, 40(3), 249-265. https://doi.org/10.17744 /mehc.40.3.06.

44. Myers, J. E., Sweeney, T. J., \& Witmer, J. M. (2000). The wheel of wellness counseling for wellness: A holistic model for treatment planning. Journal of Counseling \& Development, 78(3), 251-266. https://doi.org/10.1002/j.1556-6676.2000.tb01906.x.

45. Kerns, R. D., Brandt, C. A., \& Peduzzi, P. (2019). NIH-DoD-VA pain management collaboratory. Pain Medicine, 20(12), 23362345. https://doi.org/10.1093/pm/pnz186.

46. Shim, R., \& Rust, G. (2013). Primary care, behavioral health, and public health: Partners in reducing mental health stigma. American Journal of Public Health, 103(5), 774-776. https://doi. org/10.2105/ajph.2013.301214.

47. Hunt, M. G., Cuddeback, G. S., Bromley, E., Bradford, D. W., \& Hoff, R. A. (2019). Changing rates of mental health disorders among Veterans treated in the VHA during troop drawdown, 2007-2013. Community Mental Health Journal, 55(7), 11201124. https://doi.org/10.1007/s10597-019-00437-1.
48. Outcalt, S., Kroenke, K., Krebs, E., Chumbler, N., Wu, J., Yu, Z., et al. (2015). Chronic pain and comorbid mental health conditions: independent associations of posttraumatic stress disorder and depression with pain, disability, and quality of life. Journal of Behavioral Medicine, 38(3), 535-543. https://doi.org/10.1007/ s10865-015-9628-3.

49. Yoon, J., Bruckner, T. A., \& Brown, T. T. (2013). The association between client characteristics and recovery in California's Comprehensive Community Mental Health Programs. American Journal of Public Health, 103(10), e89-e95. https://doi.org/10.2105/ ajph.2013.301233.

50. Schmit, M. K., Watson, J. C., \& Fernandez, M. A. (2018). Examining the effectiveness of integrated behavioral and primary health care treatment. Journal of Counseling \& Development, 96(1), 3-14. https://doi.org/10.1002/jcad.12173.

51. Müller, R., Landmann, G., Bechir, M., Hinrichs, T., Arnet, U., Jordan, X., et al. (2017). Chronic pain, depression and quality of life in individuals with spinal cord injury: Mediating role of participation. Journal of Rehabilitation Medicine, 49, 489-496.

52. Nguyen, U.-S. D. T., Perneger, T., Franklin, P. D., Barea, C., Hoffmeyer, P., \& Lübbeke, A. (2019). Improvement in mental health following total hip arthroplasty: the role of pain and function. BMC Musculoskeletal Disorders, 20(1), 307. https://doi. org/10.1186/s12891-019-2669-y.

53. Fujii, T., Oka, H., Katsuhira, J., Tonosu, J., Kasahara, S., Tanaka, S., et al. (2018). Association between somatic symptom burden and health-related quality of life in people with chronic low back pain. PLoS ONE, 13(2), e0193208. https://doi.org/10.1371/journ al.pone.0193208.

54. Börsbo, B., Peolsson, M., \& Gerdle, B. (2009). The complex interplay between pain intensity, depression, anxiety and catastrophising with respect to quality of life and disability. Disability and Rehabilitation, 31(19), 1605-1613. https://doi.org/10.1080/09638 280903110079.

55. Shelton, C. J., Kim, A., Hassan, A. M., Bhat, A., Barnello, J., \& Castro, C. A. (2020). System-wide implementation of telehealth to support military Veterans and their families in response to COVID-19: A paradigm shift. Journal of Military, Veteran and Family Health,. https://doi.org/10.3138/jmvfh.CO19-003.

56. James Riegler, L., Raj, S. P., Moscato, E. L., Narad, M. E., Kincaid, A., \& Wade, S. L. (2020). Pilot trial of a telepsychotherapy parenting skills intervention for veteran families: Implications for managing parenting stress during COVID-19. Journal of Psychotherapy Integration, 30(2), 290-303. https://doi.org/10.1037/int00 00220.

57. Marini, C. M., Pless Kaiser, A., Smith, B. N., \& Fiori, K. L. (2020). Aging veterans' mental health and well-being in the context of COVID-19: The importance of social ties during physical distancing. Psychological Trauma: Theory, Research, Practice, and Policy, 12(S1), S217-S219. https://doi.org/10.1037/tra00 00736.

58. U.S. Department of Veterans Affairs (2016). Profile of veterans: 2014 data from the American Community Survey. Retrieved August 8, 2020, from https://www.va.gov/vetdata/docs/Speci alReports/Profile_of_Veterans_2014.pdf.

Publisher's Note Springer Nature remains neutral with regard to jurisdictional claims in published maps and institutional affiliations. 